\title{
Fault Tolerant Power Converter Topologies for Sensor-less Speed Control of PMSM Drives
}

\author{
Mongi Moujahed ${ }^{1 *}$, Bilel Touaiti ${ }^{1}$ Hechmi Ben Azza'1, Mohamed Jemli ${ }^{1}$ Mohamed Boussak² \\ ${ }^{1}$ Laboratory of Engineering of Industrial Systems and Renewable Energies (LISIER), The National Higher Engineering School of \\ Tunis (ENSIT), University of Tunis, 5 Street Taha Hussein, BP 56, Montfleury, 1008 Tunis, Tunisia \\ ${ }^{2}$ Laboratory of Computer Sciences and Systems (LIS), Central School of Marseille, \\ 38 Street Frederic Joliot Curie, 13013 Marseille, France \\ * Corresponding author, e-mail: mongi.moujahed@yahoo.com
}

Received: 21 March 2019, Accepted: 28 May 2019, Published online: 15 August 2019

\begin{abstract}
This paper exhibits a sensor-less speed control method based MRAS observer applied to a fault-tolerant PMSM drive system. So, this paper proposes a rapid method of fault switch detection in the power converters aiming to make sure the continuity of service even though the fault presence of an opening phase. In fact, the MRAS observer is used to replace the mechanical sensor and a redundant inverter leg is equally employed to replace the faulty leg. The proposed fast fault diagnosis method has the features of simple algorithm, independence of the transient states and being simply integrated without any additional sensors.
\end{abstract}

Keywords

Permanent Magnet Synchronous Machine (PMSM), Direct Torque Control (DTC-SVM), FTC, MRAS

\section{Introduction}

Actually, the permanent magnet synchronous motors (PMSM) are efficiently applied to various applications as the electric vehicles, the aerospace industry, the medical service and the military applications thanks to several outstanding characteristics. However, the human life damages and the cost will become definitely serious, if a failure of the drive system takes place in these applications. It is evidence because of the importance of high reliable operation in these areas. Subsequently, it is an urgent need to search a fault control to improve the electrical motor performances [1-3]. In the literature, the multitudes of control solutions for PMSM have already been investigated accordingly. The DTC-SVM controls are so powerful; they are insensitive to parameters changes of the machines and robust against to the disturbance. They are even able to reduce the ripples of the flux and the torque compared to the classical DTC [4-6].

Indeed, the main objective of this DTC-SVM technique is to make a controller of stator flux vector in a fixed $(\alpha, \beta)$ reference. Afterwards, the polar forms of these two vectors are achieved only through their projections on the reference frame $(\alpha, \beta)$. Hence, the desired increment of the stator flux vector at a given time is calculated out of these components.
Additionally, a sensor-less control with MRAS is introduced so as to reduce the hardware complexity and the size of the drives as well. Furthermore, it rules out the sensor cable, enhances the reliability and decreases the maintenance requirements [7-9].

In the literature, statistic results show that about $40 \%$ of the failures in variable speed ac drives in industrial systems are concentrated in power electronics. Sometimes, if no redundant equipment is already available, a rapid shutdown of the industrial systems has occurred. This stop is accompanied by the loss of production and an unavoidable cost of repair. Consequently, given the importance of power converter safety operation in several fields such as electric traction, renewable energy and so forth it is necessary to examine availability of these industrial systems in the case of shutdown of an IGBT module, a converter leg or a phase machine. Thus, this paper proposes a novel fault diagnosis approach allows the PMSM drive of operating after fault occurrence. The proposed approach is advantageous in that it does not require additional sensors, complex hardware or complex calculations. 


\section{PMSM Model}

The $d-q$ axis stator flux linkages in the synchronous reference frame can be expressed as follows:

$\Phi_{d}=L_{d} i_{d}+K_{e}$

$\Phi_{q}=L_{q} i_{q}$

The $d-q$ axis voltage equations in the synchronous reference frame may be expressed as:

$v_{d}=R_{s} i_{d}+L_{d} \frac{d i_{d}}{d t}-\omega_{r} L_{q} i_{q}$

$v_{q}=R_{s} i_{q}+L_{q} \frac{d i_{q}}{d t}+\omega_{r}\left(L_{d} i_{d}+K_{e}\right)$

where $K_{e}=\sqrt{\frac{3}{2}} \widehat{\Phi}_{m}$.

Using Eqs. (1) and (2), electromagnetic torque is given by

$T_{e}=\frac{3}{2} p\left(K_{e} i_{q}+\left(L_{d}-L_{q}\right)\right) i_{d} i_{q}$

$\frac{d i_{d}}{d t}=\frac{R_{s}}{L_{d}} i_{d}+\frac{L_{q}}{L_{d}} \omega_{r} i_{q}+\frac{v_{d}}{L_{d}}$

$\frac{d i_{q}}{d t}=-\frac{R_{s}}{L_{q}} i_{q}-\frac{L_{d}}{L_{q}} \omega_{r} i_{q}-\frac{K_{e}}{L_{q}} \omega_{r}+\frac{v_{q}}{L_{q}}$

$\frac{d \omega_{r}}{d t}=-p^{2}\left(\frac{L_{d}-L_{q}}{J}\right) i_{d}+p^{2} \frac{K_{e}}{J} i_{q}-\frac{f}{J} \omega_{r}+p \frac{T_{l}}{J}$.

\section{Fault tolerant inverter (FTI)}

Fig. 1 shows mainly a three-phase standard six-switch inverter, enriched by with three fuses and three TRIACs. In healthy mode, the structure of the presented DTC-SVM fault tolerant inverter is equally the same as a standard three-phase six switches inverter. The adopted inverter fault tolerant control has the objective to accommodate the opening of a phase fault or a short circuit. Subsequently, we considered only the open phase fault (phase A) case in this paper. Similarly, the same procedure is applied to the phase $\mathrm{B}$ and phase $\mathrm{C}$.

Moreover, Fig. 2 displays the new inverter topology, after a fast detection and an isolation of the open phase (phase A) [7]. In this paper, we studied two cases successively: the healthy and the faulty modes.

In this paper a methodology for isolating the faulty switching device was proposed where the phase with a faulty switch is isolated and connected to the midpoint of

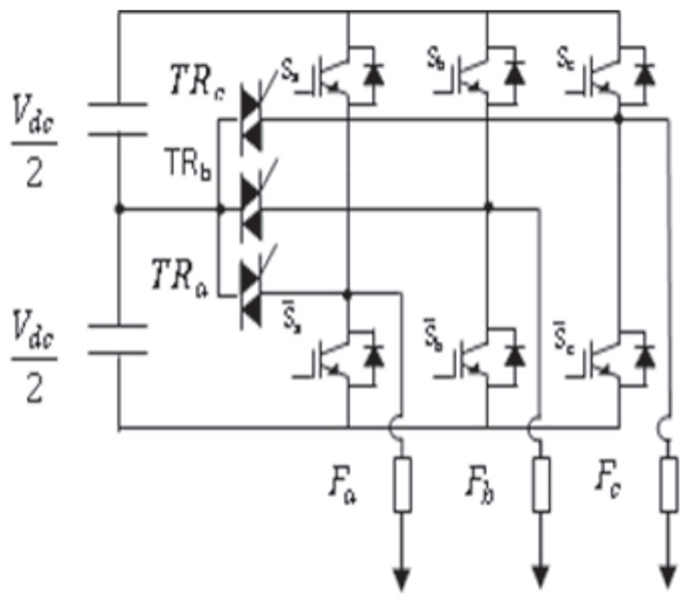

Fig. 1 Healthy mode inverter

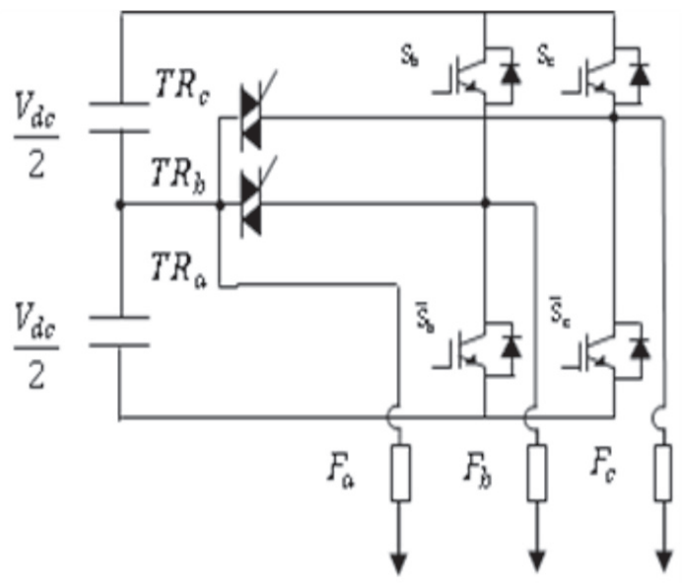

Fig. 2 Fault tolerant inverter fed PMSM drive

DC link. During the post-fault operation three phase currents are still shifted by 120 electrical degrees as in the normal healthy operation. During the post-fault operation the voltage applied to the machine terminals is reduced. However, since all three phases contribute to torque production under fault condition the current rating in this case for producing the rated torque is the same as that in the healthy condition. Consequently, the size and rate of the IGBT switches remain the same as the standard inverter.

\section{Model reference adaptive system}

During the operation of an electrical machine, the parameters can be easily changed and its performance decreases remarkably. As consequence, the MRAS can resolve this problem as it (The Model Reference Adaptive System (MRAS)) is a significant observer [10-13]. Relying on the Eqs. (6) and (7), the state model is the stator current that is chosen as a variable state is: 


$$
\left[\begin{array}{c}
\frac{d i_{d}}{d t} \\
\frac{d i_{q}}{d t}
\end{array}\right]=\left[\begin{array}{cc}
-\frac{R_{s}}{L_{d}} & \frac{L_{q}}{L_{d}} \omega_{r} \\
-\frac{L_{d}}{L_{q}} \omega_{r} & -\frac{R_{s}}{L_{q}}
\end{array}\right]\left[\begin{array}{l}
i_{d} \\
i_{q}
\end{array}\right]+\left[\begin{array}{c}
\frac{V_{d}}{L_{d}} \\
\frac{V_{q}}{L_{q}}-\frac{K_{e}}{L_{q}} \omega_{r}
\end{array}\right]
$$

where

$$
\begin{aligned}
& i_{d}^{*}=i_{d}+\frac{K_{e}}{L_{d}}, \quad i_{q}^{*}=i_{q} \\
& V_{d}^{*}=V_{d}+\frac{K_{e}}{L_{d}} R_{s}, \quad V_{q}^{*}=V_{q} .
\end{aligned}
$$

According to the general structure of the adaptation law, the $\widehat{\omega}_{r}$; can be expressed in the form of Eq. (12).

$$
\widehat{\omega} r=\int_{0}^{t} \psi 1(v, t, \tau) d \tau+\psi 2(v, t)+\widehat{\omega} r(0)
$$

Where $v$ is the output of the block. $\psi_{1}$ and $\psi_{2}$ area as follow.

$$
\left\{\begin{array}{l}
\psi_{1}(v, t)=K_{1} e^{T} L \hat{i}^{*} \\
\psi_{2}(v, t)=K_{2} e^{T} L \hat{i}^{*}
\end{array}\right.
$$

where

$$
L=\left[\begin{array}{cc}
0 & \frac{L_{q}}{L_{d}} \\
-\frac{L_{d}}{L_{q}} & 0
\end{array}\right], e=\left[\begin{array}{c}
i_{d}^{*}-\hat{i}_{d}^{*} \\
i_{q}^{*}-\hat{i}_{q}^{*}
\end{array}\right], \hat{i}^{*}=\left[\begin{array}{c}
\hat{i}_{d}^{*} \\
\hat{i}_{q}^{*}
\end{array}\right] .
$$

The estimation speed is as following

$$
\begin{aligned}
\hat{\omega} & =\left(K_{p}+\frac{K_{i}}{p}\right)\left[\frac{L_{q}}{L_{d}} i_{d} \hat{i}_{q}-\frac{L_{d}}{L_{q}} \hat{i}_{d q} i_{q}-\frac{K_{e}}{L_{q}}\left(i_{q}-\hat{i}_{q}\right)+\hat{i}_{d} \hat{i}_{q}\left(\frac{L_{d}}{L_{q}}-\frac{L_{q}}{L_{d}}\right)\right] \\
& +\hat{\omega}(0) .
\end{aligned}
$$

Relying on Eqs. (14) and (15), the block diagram control of the PMSM is based on MRAS can be obtained in Fig. 3.

\section{Direct torque control space vector modulation}

The DTC-SVM improves greatly the torque and the flux performance through the achieved and the fixed switching frequency and the decreased torque and the flux ripples as well.

$$
T_{e}=\frac{3}{2} n_{p}\left[\frac{\left|\underline{\Phi}_{s}\right| K_{e} \sin \delta}{L_{d}}-\frac{\left|\underline{\Phi}_{s}\right|^{2}\left(L_{q}-L_{d}\right) \sin (2 \delta)}{2 L_{d} L_{q}}\right]
$$

From the Eq. (16), we can see that the constant stator flux amplitude $\left|\underline{\Phi}_{s}\right|$ and the flux produced by permanent magnet $K_{e}$, the electromagnetic torque can be changed by the control of the torque angle $\delta$. If the stator resistance is neglected, the torque angle is between the stator and rotor flux linkage.

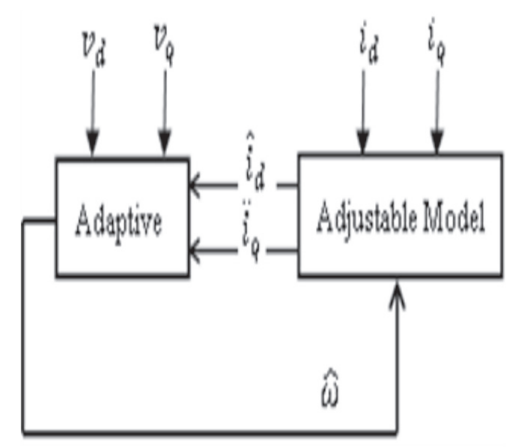

Fig. 3 The block diagram control of the PMSM is based on MRAS

The torque angle by the way can be replaced just by changing the position of the stator flux vector $\theta_{c}$ in respect to PM vector using the actual voltage vector supplied by PWM inverter. In the steady state, $\delta$ is constant and corresponds to a load torque whereas stator and rotor flux rotate at synchronous speed. In transient operation, $\delta$ varies and the stator and rotor flux rotate at different speeds (Fig. 4).

The relationship between the torque error and the increment of the load angel $\delta$ is a nonlinear. Therefore, we use PI controller that generates the load angel increment required to minimize the instantaneous error between the reference $T_{e_{-} \text {ref }}$ and the actual $T_{e}$ torque.

Thereby, the torque error signal $\Delta T_{e}$ is delivered to the PI controller, which determines the increment of the torque angle $\delta$. Relying on this signal and reference amplitude of stator flux $\Phi_{e \text { ref }}$, the reference voltage vector in stator coordinates $\alpha, \beta$ is determined. In addition, the calculation block of the reference voltage vector also uses data about the actual stator flux vector (amplitude $\Phi_{s}$ and position $\theta_{s}$ ) as well as the measured current vector $I_{s}$. Hence, the reference stator voltage vector is delivered to the space vector modulator (SVM) which generates the switching signals $S_{a}, S_{b}$ and $S_{c}$ for the power transistors of inverter. As well as, the calculation block of reference voltage vector is shown in Fig. 5.

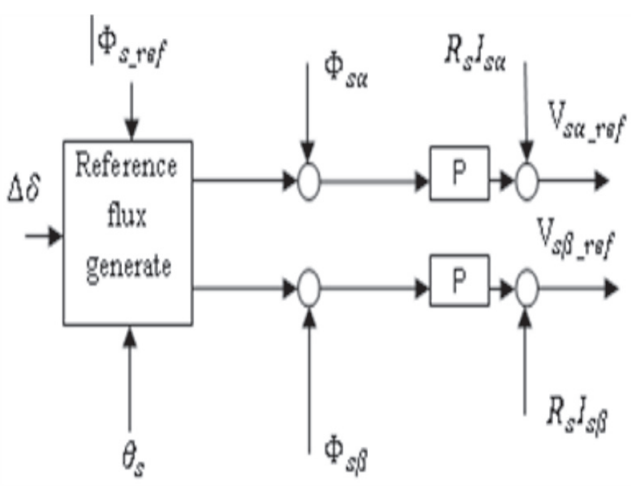

Fig. 4 Calculation block of the reference voltage vector 


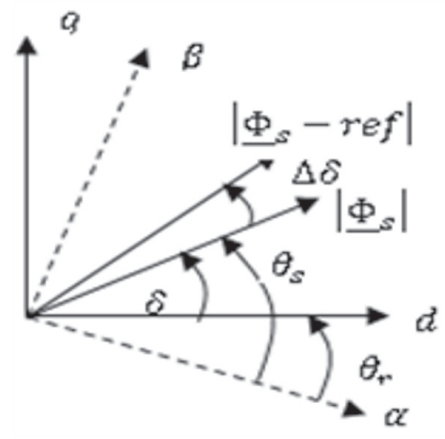

Fig. 5 Space Vector Diagram illustrating Torque Control Conditions

Depending on the $\Delta \delta$ signal, the reference of stator flux amplitude to $\Delta \delta$ signal, the reference of stator flux amplitude $\left|\Phi_{s_{-} r e f}\right|$, the measured stator flux vector position $\theta_{s}$ (Fig. 5) the reference flux components $\Phi_{s \alpha_{-} r e f}, \Phi_{s \beta_{-} r e f}$ in stator coordinate system are calculated as:

$\left\{\begin{array}{l}\Phi_{s \alpha-r e f}=\left|\Phi_{s-r e f}\right| \cos (\theta s+\Delta \delta) \\ \Phi_{s \beta-r e f}=\left|\Phi_{s-r e f}\right| \sin (\theta s+\Delta \delta)\end{array}\right.$

For a constant flux operation region, the reference value of stator flux amplitude $\left|\Phi_{s_{-} \text {ref }}\right|$ is equal to flux amplitude of permanent magnet $K_{e}$.

The command voltage can be determined from the flux errors in $\alpha, \beta$ coordinate system as following.

$\left\{\begin{array}{l}v_{s \alpha-r e f}=\frac{\Delta \Phi_{s \alpha}}{T_{s}}+R_{s} I_{s \alpha} \\ v_{s \beta-r e f}=\frac{\Delta \Phi_{s \beta}}{T_{s}}+R_{s} I_{s \beta}\end{array}\right.$

Where $T_{s}$ is the sampling time, $\Delta \Phi_{s \alpha}=\Phi_{s \alpha_{-} r e f}-\Phi_{s \alpha}$ and $\Delta \Phi_{s \beta}=\Phi_{s \beta_{-} r e f}-\Phi_{s \beta}$.

The structure of the proposed control schema, which is presented in this paper is shown in the Fig. 6.

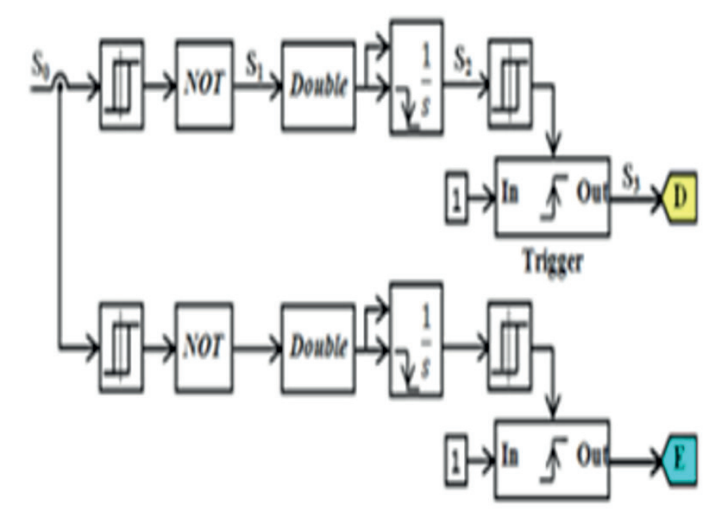

Fig. 6 Fault Detection Isolation Algorithm (FDI)

\section{Fault tolerant control}

The design and the modeling of some faults types in the electric actuators and particularly in the inverter faults (component faults) are very important tasks. Subsequently, the development of the control strategy is able to detect, to isolate and to ensure the continuity of functioning of the system, which becomes a necessity. Many studies have been already conducted to detect an electrical fault in the machine, in the inverter and in the power circuits. Hence, each fault generates one or more perturbations. Therefore, the detection out of that should be traceable to the fault. The choice and the desired signature extraction method differ from one technique to another. The open circuit faults are identifiable from their observed measuring currents and lead to a current decrease as a result (or voltage) on the faulty phase signatures.

If the abnormal operation is detected, the fault is localized with some specific test loop at each leg inverter, which allows knowing the IGBT module where the fault occurred. Fig. 6 shows the applied technique (series of tests) for fault detection and localization using the same operations and signal generation for the intervention of these fault tolerant control [14-16].

S0: Represents the signal of the measured current on phase a. (the same thing for a and c phase)

D, E: Represents the signal (1or 0 logic) to control signal of triacTRa.

The schematic diagram for generating the control signals of triacs is given by Fig. 7. Using the two signals generated by the FDI algorithm, for example, the control signal of triacTRa is set to 1 . The triacTRa is used to connect the redundant leg.

The performance of system after fault occurrence in TRIACs is similar to the one-phase open-circuit fault.

When this fault occurs, during the faulty mode only the faulty phase current become zero while the healthy phase have increased magnitudes.

After the fault occurrence, the ripples of the torque are bigger than that under the safe inverter. This fault may also produce a small real speed ripples. Consequently, the

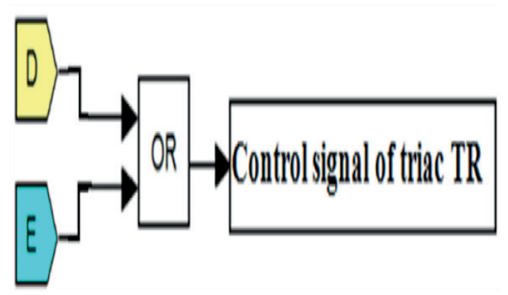

Fig. 7 Schematic diagram for generating the control signals of triacs 
fault conditions cause abnormal rotor vibrations and give abnormalities in the drive's operation.

The reconfiguration of drive system can be realized by acting on its control algorithm of this type of fault.

\section{Simulation results}

\subsection{Healthy mode}

The simulation results of the proposed control, previously discussed under the inverter fault has been carried out with the scheme block Fig. 8 relying on Matlab/Simulink. The drive system is composed of a PMSM (parameters are listed in Table 1) and a fault tolerant inverter as shown in Fig. 1.

\subsection{Open phase faulty mode}

After the fault occurrence, the ripples of the torque are bigger than that under the safe inverter. This fault may also produce a small real speed ripples. Consequently, the fault conditions cause abnormal rotor vibrations and give abnormalities in the drive's operation. Simulation results of the line currents $\left(i_{a}, i_{b}\right.$ and $\left.i_{c}\right)$. As from the occurrence of fault at $t=0.75 \mathrm{~s}$, the magnitude of stator currents increases, the current $i_{a}$ becomes zero, while $i_{b}$ and $i_{c}$ undergo a slight deformation.

\subsection{Fault tolerant control}

The capacitors in the DC-link are really assumed to be infinite so that the voltage on both capacitors is constant and equal to $\frac{V_{d c}}{2}$.

In the first test, Fig. 9 shows a typical start-up of the PMSM with no fault. The reference rotor speed is set up at $1500 \mathrm{rpm}$ with a nominal load torque step $T_{l}=4 \mathrm{Nm}$ applied to the system at time $t=0.4 \mathrm{~s}$. As Fig. 8 displays that the speed drop at the time of applying a load torque does not exceed $4 \%$, the duration of the disturbance does not exceed 0.6 s. While Fig. 10 exhibits additionally the waveforms of the electromagnetic torque, Fig. 11 illustrates the waveforms of the currents $i_{a}$.

In the second test, the PMSM started without load torque and then a nominal load torque is applied at $0.4 \mathrm{~s}$.

An open phase fault is created by a cutting of motor power phase. Consequently, the open phase fault of the PMSM introduced an unbalance in the stator winding currents. Like it's shown in the Fig. 12, the machine continues to rotate with oscillations as a consequence of the huge oscillations in the torque. Finally, faults in IGBTs generally do not cause system shutdown, but degrade its performances. The Fig. 13 shows the rotor speed, Fig. 14 the stator currents, Fig. 12 the electromagnetic of the PMSM
Table 1 PMSM Parameters

\begin{tabular}{|c|c|c|c|}
\hline & Parameters & Specification & \\
\hline$R_{s}$ & $0.5 \Omega$ & Rated power & $1.570 \mathrm{~kW}$ \\
\hline$L_{d}$ & $3.9 \mathrm{mH}$ & Rated voltage & $400 \mathrm{~V}$ \\
\hline$L_{q}$ & $3.7 \mathrm{mH}$ & Rated current & $5.9 \mathrm{~A}$ \\
\hline$K_{t}$ & $0.910 \mathrm{Nm} / \mathrm{A}$ & $\mathrm{Vdc}$ & $540 \mathrm{~V}$ \\
\hline$K_{e}$ & 0.2275 V.s $/ \mathrm{rad}$ & Number of pole pairs & 4 \\
\hline$J$ & $5.810^{-4} \mathrm{Kg} \cdot \mathrm{m}^{2}$ & Rated speed & $3000 \mathrm{rpm}$ \\
\hline$f$ & $0.00374 \mathrm{Nm} . / \mathrm{rad}$ & Rated torque & $5 \mathrm{Nm}$ \\
\hline
\end{tabular}

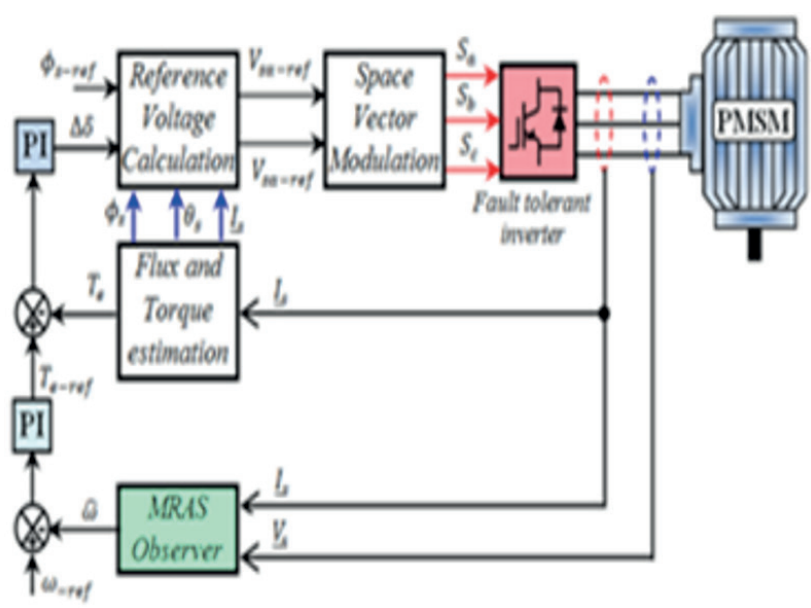

Fig. 8 SVM based DTC control scheme for PMSM

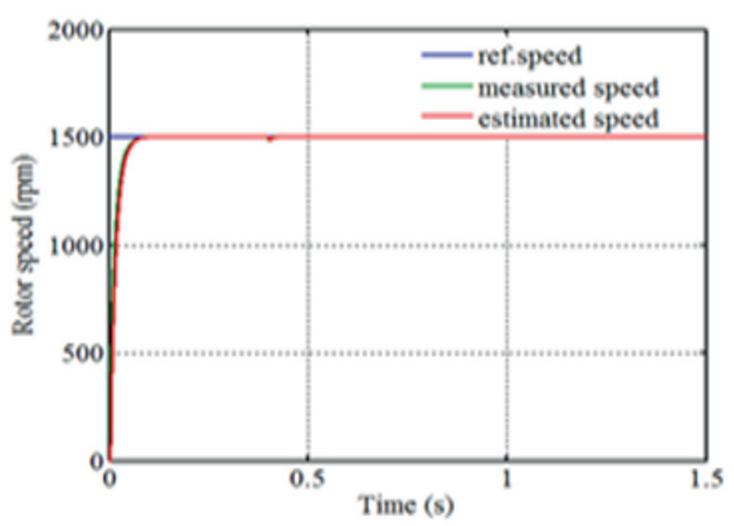

Fig. 9 Waveform of speed

to an open phase fault. As shown prior in the Fig. 10, the machine keeps rotating enormously with huge oscillations in the torque. In FTC mode, after having shown that the system does not able to function in case of a failure, this section shows results of the inverter reconfiguration; Fig. 17 shows the simulation results under the same conditions (the reference rotor speed is set at $1500 \mathrm{rpm}$ with a nominal load torque step $T_{l}=4 \mathrm{Nm}$ ) relying on an open phase. However, we note a presence of disturbances in the amplitudes of the currents at the time of fault and the removal of the positive alternating of $i_{a}$ current which 


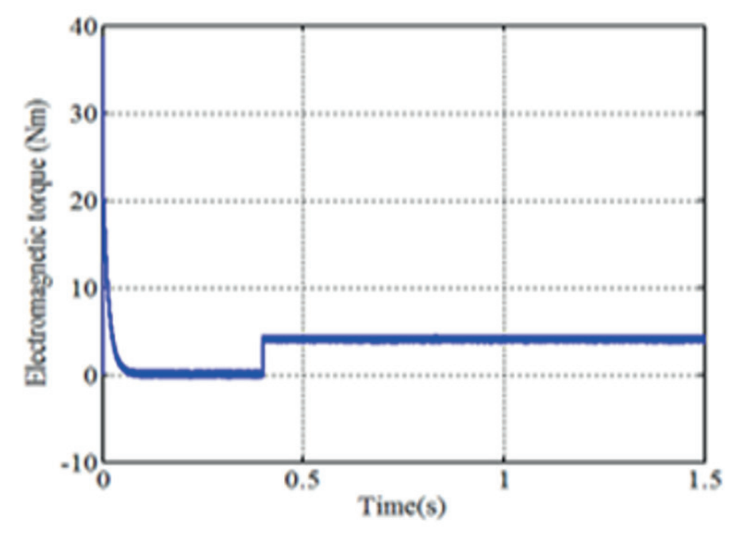

Fig. 10 Waveform of electromagnetic torque

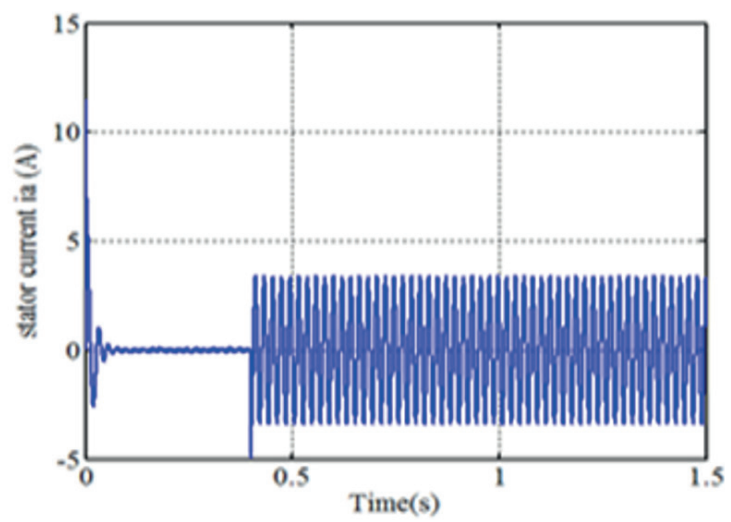

Fig. 11 Waveform of the stator current

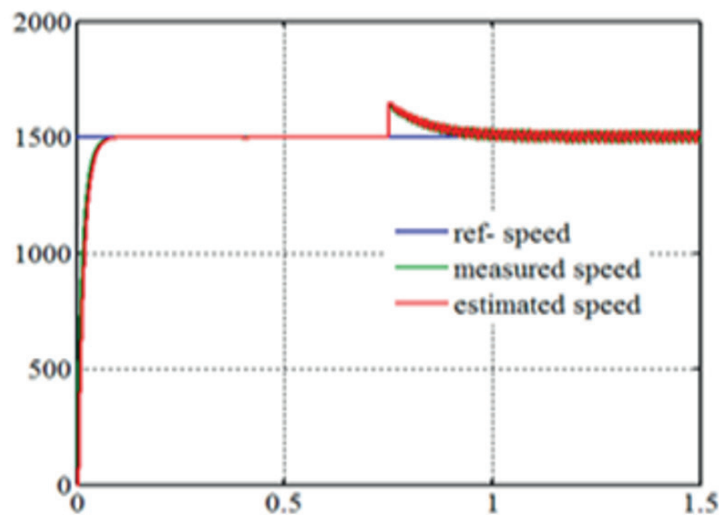

Fig. 12 Waveform of the electromagnetic torque

returns to its nominal value after a few milliseconds (Fig. 17) only when the changeover takes place (response time of the tolerant control faults - time required for diagnosis). We note also large variations in the torque of the machine that accompanies a speed slowdown in (Fig. 18).

This controller is able to tolerate a fault relying on the obtained results during the application of our FTC where there is a conservation of its performance since all the variables return to their nominal states.

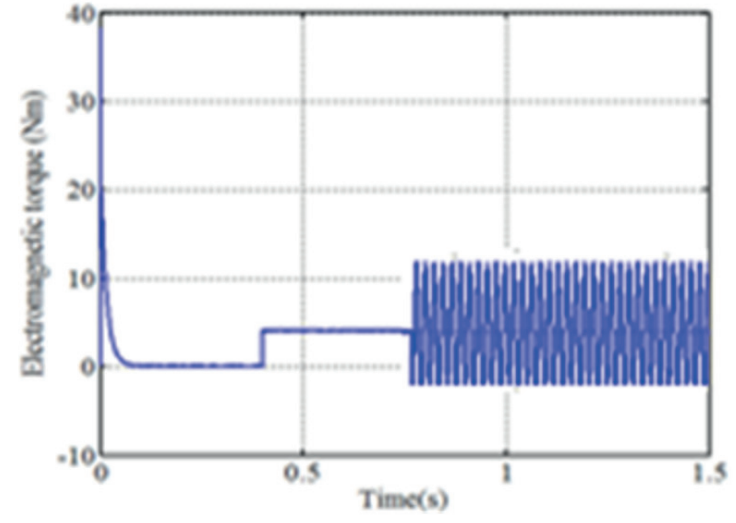

Fig. 13 Waveform of the speed

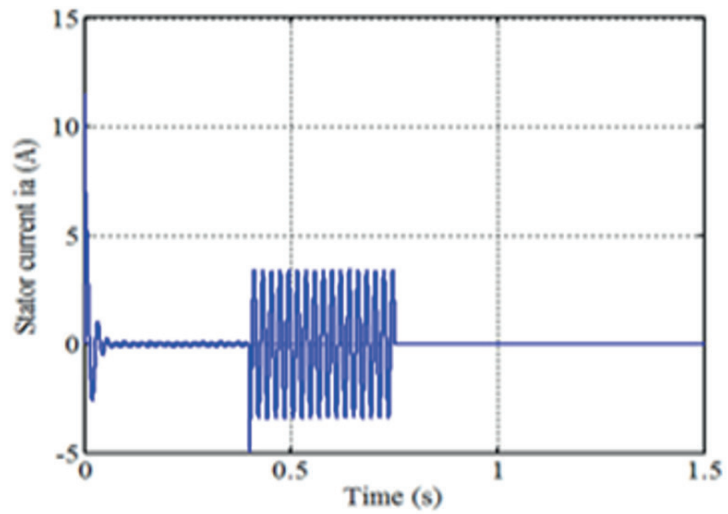

Fig. 14 Wave form of the stator current phase a

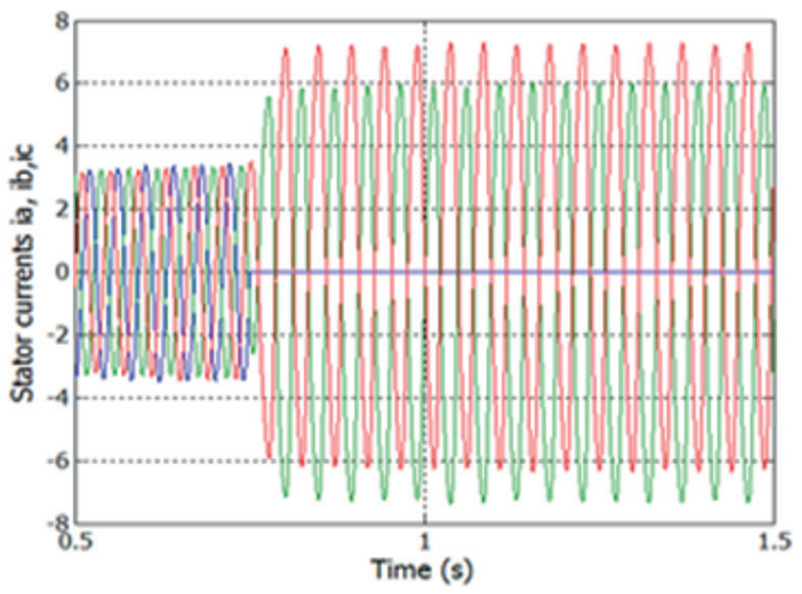

Fig. 15 Wave form of the stator currents phase a,b,c

\section{Conclusion}

Eventually, this paper has presented a fault tolerant voltage source inverter, which can compensate faults in the switching devices. A comparison between the behaviors of the machine corresponds to the operation in both the healthy and the degraded modes with the presence and the absence of the fault, has been done. A sensor-less control 


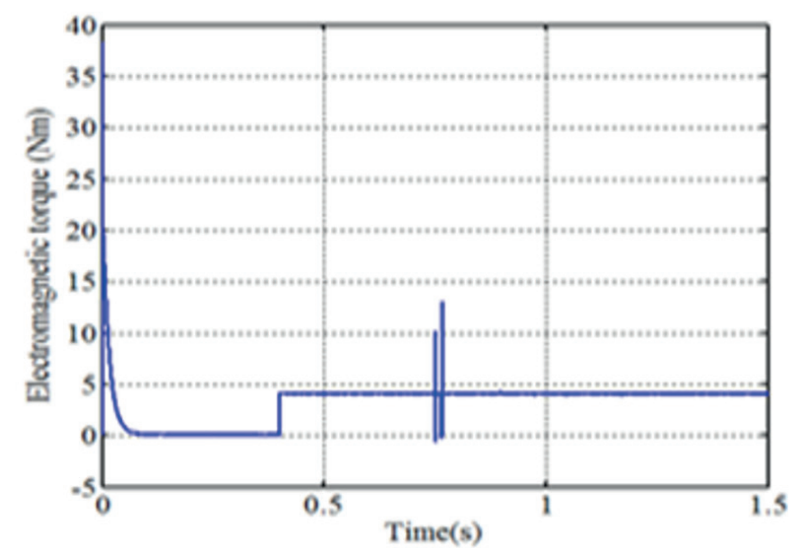

Fig. 16 Wave form of the torque

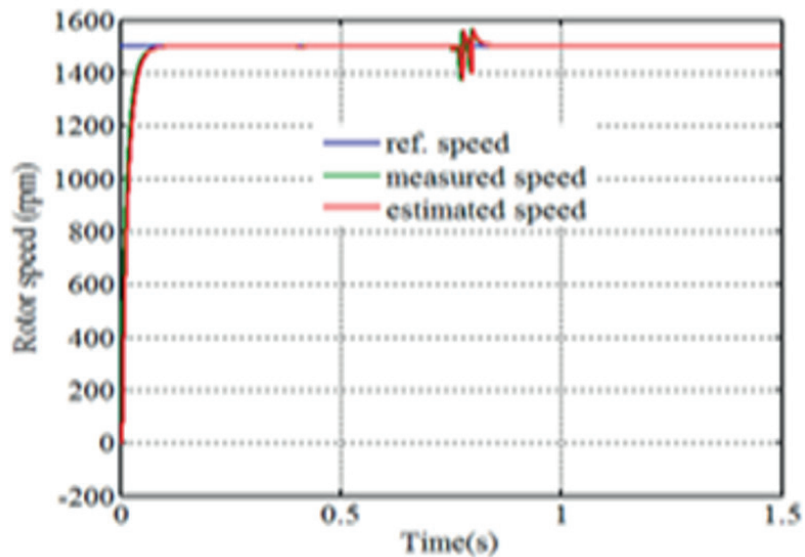

Fig. 17 Wave form of the speed

is based also on MRAS. Thereafter, the simulation results demonstrate that the proposed algorithms have good static and dynamic performances.

\section{References}

[1] Sun, D., He, Z., He, Y., Guan, Y. "Four-Switch Inverter Fed PMSM DTC with SVM approach for Fault Tolerant operation", In: 2007 IEEE International Electric Machines \& Drives Conference, Antalya, Turkey, 2007, pp. 295-299. https://doi.org/10.1109/IEMDC.2007.382682

[2] Sun, D., He, Y. "A modified direct torque control for PMSM under inverter fault", In: 2005 International Conference on Electrical Machines and Systems, Nanjing, China, 2005, pp. 2469-2473. https://doi.org/10.1109/ICEMS.2005.203019

[3] Zhu, Z. Q., Utaikaifa, K., Hoang, K., Liu, Y., Howe, D. "Direct torque control of three-phase PM brushless AC motor with one phase open circuit fault", In: 2009 IEEE International Electric Machines and Drives Conference, Miami, FL, USA, 2009, pp. $1180-1187$.

https://doi.org/10.1109/IEMDC.2009.5075353

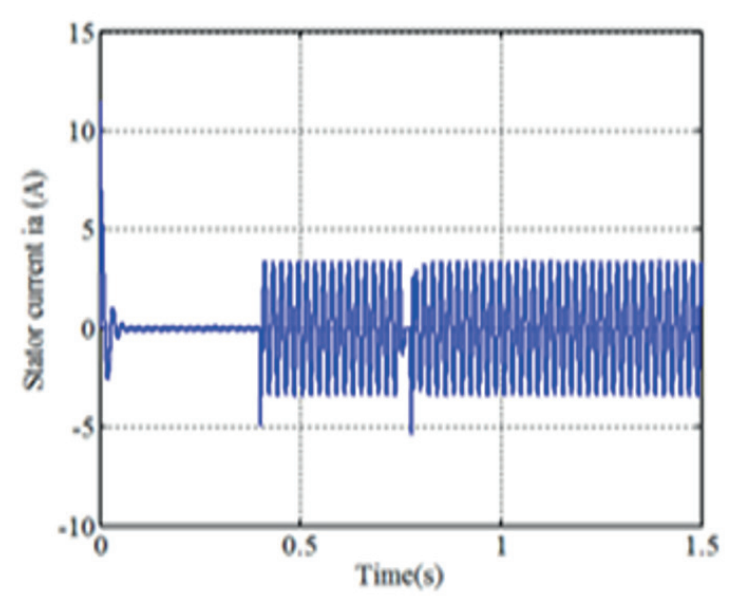

Fig. 18 Wave form of the stator current phase a

\section{Nomenclature}

$d-q \quad$ synchronous axis reference frame quantities

$i_{d}, i_{q} \quad$ stator $d$ and $q$ axis currents

$v_{d}, v_{q} \quad$ stator $d$ and $q$ axis voltages

$\Phi_{d}, \Phi_{q} \quad$ stator $d$ and $q$ axis flux linkages

$L_{d}, L_{q} \quad$ stator $d$ and $q$ axis inductances

$\widehat{\Phi}_{m} \quad$ peak permanent magnet flux linkage

$K_{e} \quad$ Back-EMF coefficient constant

$K_{t} \quad$ torque constant

$R_{s} \quad$ stator resistance

$J \quad$ total rotor inertia

$f \quad$ viscous friction coefficient

$p \quad$ number of the pole pairs

$\theta_{r} \quad$ electrical rotor position

$\omega_{r} \quad$ electrical rotation speed

$T_{e} \quad$ electromagnetic torque

$T_{s} \quad$ sampling time

[4] Khwan-on, S., de Lillo, L., Empringham, L., Wheeler, P., Gerada, C., Othman, N. M. D., Jasim, O., Clare, J. "Fault tolerant power converter topologies for PMSM drives in aerospace applications", In: 2009 13th European Conference on Power Electronics and Applications, Barcelona, Spain, 2009, pp. 1-9.

[5] Buja, G. S., Kazmierkowski, M. P. "Direct torque control of PWM inverter-fed AC motors-A survey", IEEE Transactions on Industrial Electronics, 51(4),pp. 744-757, 2004.

https://doi.org/10.1109/TIE.2004.831717

[6] Tang, L., Zhong, L., Rahman, M. F., Hu, Y. "A novel direct torque controlled interior permanent magnet synchronous machine drive with low ripple in flux and torque and fixed switching frequency", IEEE Transactions on Power Electronics, 19(2), pp. 346-354, 2004.

https://doi.org/10.1109/TPEL.2003.823170 
[7] Welchko, B. A., Lipo, T. A., Jahns, T. M., Schulz, S. E. "Fault tolerant three-phase $\mathrm{AC}$ motor drive topologies: a comparison of features, cost, and limitations", IEEE Transactions on Power Electronics, 19(4), pp. 1108-1116, 2004.

https://doi.org/10.1109/TPEL.2004.830074

[8] Aygün, H., Gökdag, M., Aktas, M., Cernat, M. "A novel sensorless field oriented controller for Permanent Magnet Synchronous Motors", In: 2014 IEEE 23rd International Symposium on Industrial Electronics (ISIE), Istanbul, Turkey, 2014, pp. 715-720. https://doi.org/10.1109/ISIE.2014.6864700

[9] Guitard, J., Richard, F., Bouallaga, K. "Fault-tolerant inverter with real-time monitoring for aerospace applications", In: 14th International Power Electronics and Motion Control Conference EPE-PEMC 2010, Ohrid, Macedonia, 2010, pp. T9-1-T9-6. https://doi.org/10.1109/EPEPEMC.2010.5606827

[10] Azab, M., Orille, A. L. "Novel flux and torque control of induction motor drive using four switch three phase inverter", In: IECON'01. 27th Annual Conference of the IEEE Industrial Electronics Society (Cat. No.37243), Denver, CO, USA, 2001, pp. 1268-1273. https://doi.org/10.1109/IECON.2001.975964

[11] Bahri, I., Slama-Belkhodja, I., Monmasson, E. "FPGA-based realtime simulation of fault tolerant current controllers for power electronics", In: 2009 IEEE International Symposium on Industrial Electronics, Seoul, 2009, pp. 378-383. https://doi.org/10.1109/ISIE.2009.5222730
[12] Bolognani, S., Zordan, M., Zigliotto, M. "Experimental fault-tolerant control of a PMSM drive", IEEE Transactions on Industrial Electronics, 47(5), pp. 1134-1141, 2000. https://doi.org/10.1109/41.873223

[13] Meinguet, F., Gyselinck, J. "Control strategies and reconfiguration of four-leg inverter PMSM drives in case of single-phase open-circuit faults", In: 2009 IEEE International Electric Machines and Drives Conference, Miami, FL, USA, 2009, pp. 299-304. https://doi.org/10.1109/IEMDC.2009.5075221

[14] Ertugrul, N., Soong, W., Dostal, G., Saxon, D. "Fault tolerant motor drive system with redundancy for critical applications", In: 2002 IEEE 33rd Annual IEEE Power Electronics Specialists Conference, Cairns, Qld., Australia, 2002, pp. 1457-1462. https://doi.org/10.1109/PSEC.2002.1022381

[15] Moujahed, M., Ben Azza, H., Frifita, K., Jemli, M., Boussak, M. "Fault detection and fault-tolerant control of power converter fed PMSM", Electrical Engineering, 98(2), pp. 121-131, 2016. https://doi.org/10.1007/s00202-015-0350-5

[16] Moujahed, M., Ben Azza, H., Jemli, M., Boussak, M. "Implementation of Improved Sliding Mode Observer and Fault Tolerant Control for a PMSM Drive", Journal of Circuits, Systems and Computers, 26(2), Article ID: 1750032, 2017.

https://doi.org/10.1142/S0218126617500323 